\title{
OBE Curriculum Scheme Design of Application Software Development Based on Java in CDIO Mode
}

\author{
Qiuyun Zhao ${ }^{1, a}$, Lei Wei ${ }^{1, b}$ \\ ${ }^{1}$ School of Computer, Chengdu University of Information Technology, Chengdu, China \\ azqyuen@cuit.edu.cn, bweile@cuit.edu.cn \\ * Qiuyun Zhao
}

\begin{abstract}
Keywords: CDIO engineering education; Outcomes-based education; Course objective; Graduation standard; Teaching procedure design.
\end{abstract}

\begin{abstract}
In view of poor teaching effect of Application Software Development Based on Java, taking CDIO engineering education as an opportunity, the curriculum teaching scheme based on OBE is designed around the engineering education accreditation standards closely. The scheme is built taking the graduation standard as the starting point in reverse direction. Research and reform are carried out for the curriculum of Application Software Development Based on Java in several aspects, such as the curriculum supporting points for graduation requirements, the teaching procedures and the teaching stage assessment. It has proved that the program can improve the quality of the curriculum teaching course and make students' learning better.
\end{abstract}

\section{Introduction}

CDIO higher engineering education is to cultivate students' engineering ability with the whole process of 'Conceive-Design-Implement-Operate' [1]. By advocating new teaching model of 'learning by doing' and 'teaching and learning based on project', CDIO focuses on developing students' basic engineering knowledge, personal skills, team skills and engineering system capabilities and aims to train Engineers who are able to adapt to the modern society need with the engineering expertise, social awareness and the entrepreneurship and innovation spirit[2]. The core of the CDIO is a vision, an outline, and twelve guidelines[3], among which, the CDIO outline puts forward concretely that the ability training plan of each layer, the comprehensive implementation guidance and procedures, twelve standards for commenting the scheme results[4]. For standers of commenting the scheme, Most the member states (or regions) of Washington Accord adopt the certification standard of the 'results oriented'. In this way, student performance is used as a evaluation basis for teaching achievement, and it is taken as the ultimate certification goal to promote the continuous major improvement[5]. 'Output Based Education model (OBE)' is a model with output-oriented as the evaluation basis for teaching achievement, and as the purpose of promoting the professional training goal and keeping the graduation requirements continuously[6]. OBE coincides with the three core concepts identified by the orienting to output of engineering education, centralizing student and the continuous improvement. Therefore, many domestic colleges and universities have carried out the research on the teaching reform based on OBE model, and a series of research results have been obtained.

The CDIO teaching mode is introduced into the Computer Science and technology major of Chengdu University of Information Technology earlier in the domestic. As the trial major and through a few years of practice, combined with the teacher's own circumstances, a deep exploration has been done about the professional and technical personnel training system under the CDIO engineering education background and several achievement are received. In recent years, with requirements of the national engineering education accreditation, a series of reforms have been carried out by the introduction of OBE in the Computer Science and technology major.

In this paper, Application Software Development Based on Java is taken as the example. Under the CDIO mode, the OBE reform design scheme is discussed in the Computer Science and technology 
major from aspects of the curriculum objectives, the curriculum supporting points for graduation requirements, teaching procedures and the teaching link assessment.

\section{Course objectives and graduation requirements}

\subsection{Course objectives}

Application Software Development based on Java belongs to engineering practice courses, and it is a compulsory course in the computer science and technology major. The course is of the Java series. Its prerequisites include Java Language Program Design, Software Engineering, Database Principle and Database Application Technology. The follow-up curriculum is the Web Database Access Technology (Java EE). Main content of Application Software Development is the realization of an information system using the MVC architecture and the Java language.

Through study of the course, students should obtain the preliminary understanding for the software architecture, and could use Java language skillfully for software development, and could understand of object-oriented programming thought well. Students could also use the software project management knowledge to design and develop the software system for different business requirements. What's more, students' abilities to use their knowledge comprehensively, to analyze and solve problems, and to enjoy the teamwork can all be trained. The specific objectives are as follows.

Objective 1: be able to collect and analyze the application requirements according to the real business and give the appropriate expression in accordance with software engineering requirements.

Objective 2: be able to analyze and evaluate reasonable according to the business requirements and combined with the technical, social and other factors.

Objective 3: be able to design the corresponding software system in accordance with the analysis and using the MVC architecture. Design includes the function design, interface design and the database design.

Objectives 4: be able to develop the system with thought of the object oriented programming, and test and optimize the system functions.

Objectives 5: be able to manage the software design and development by the engineering project management knowledge simply.

Objectives 6: be able to take on roles in a team, collaborate with other members, and describe the project properly and accurately.

\subsection{Curriculum supporting points for graduation requirements}

According to the engineering education accreditation requirements, twelve professional graduation requirements are sorted out combined with the training objectives and this school actual situation of the computer science and technology major. Taking the course characteristics and the curriculum objective into account, four supporting points for graduation requirements are designed and shown in Table 1. 
Table 1. The curriculum supporting points for graduation requirements.

First level indexes

Second level indexes

Graduation requirement 2.Be able to apply principles of the mathematical, natural, and the computer science to identify, express, and analyze complex engineering problems through literature studies to obtain valid conclusions

Graduation requirement 3. be Able to design solutions for complex engineering problems, design software, modules and components to meet the special needs . be able to with innovation and consider the social, health, safety, legal, cultural and environmental factors.

Graduation requirement 9.Individuals and teams: Be able to undertake roles of team members or the head in a multidisciplinary team.

Graduation requirement $11 . \mathrm{Be}$ able to master knowledge of the software project management knowledge and method of the economic decision making, and apply them in multi discipline environment.
2.3 have capabilities of the bottom-up and top-down problem analysis. be able to model software and abstract into computer requirements analysis from actual needs. 2.6Be able to analyze complex engineering problems and obtain valid conclusions.

3.2be able to master the design and development processes of software and hardware. Be able to design embedded software modules / components to meet the specific needs, during which the social, health, safety, legal, cultural and environmental factors are considered. 3.3 Be able to develop software modules and embedded system components that meet specific requirements.

9.2Have experience that work with people to develop computer software modules and embedded system components. Be able to undertake the role in a team and have good sense of teamwork, the ability to organize and coordinate;

11.3 Be able to design and develop software and embedded systems using knowledge of the project management knowledge for different disciplines and industries.

\section{Design and assessment of course teaching procedures}

Application Software Development based on Java is driven by project. Students realize 'learning by doing' by applying software engineering knowledge to project development. The teaching activities are carried out by the teaching, examinations and answers, experiments, the demonstration and reply form and so on. Stage results generated periodically are considered as the evaluation factors in the project procedures. According to the software development processes, the course content covers several parts of the curriculum overview and the project introduction, the project requirement analysis, feasibility analysis, project design, software development, testing and optimization, writing project reports and the project demonstrations. The main content of each part is demonstrated here.

Curriculum overview and project introduction: Demand students to clear up the purpose of the course and specify the requirements for the whole processes. Students make groups and choose titles.

Project requirement analysis: Collect and analyze the application requirements from real businesses, and complete the project requirement analysis report.

Project feasibility analysis: Analyze and evaluate the business requirements combined with the technical, social and other factors. Complete the feasibility analysis report.

Project design: design software systems according to the MVC architecture, including the functional design (determine the functional structure), interface design (the man-machine interfaces and module interfaces in the system) and the database design (describing data features, complete the database design).

Software development, testing and optimization: Develop the corresponding software by Java language according to thought of the object-oriented programming, and test function, and further optimize the code.

Write project reports: Write project reports describing the finished job and the project management things, and summarize the project.

Project display: Make PPT presentations, demonstrate and explain the application software. 
Combining the curriculum objectives, the curriculum content, the graduation standards and the teaching procedures, the curriculum teaching procedures are designed as follows corresponding course syllabus.

(i) Curriculum objective 1 would be made by the poject requirements analysis chapter corresponding course syllabus. The curriculum supporting points for graduation requirements (Second level) is the 2.3. The teaching procedures include the normal teaching, checking and Q \& A and experiment. The assessment link of the procedure is the intermediate document.

(ii) Curriculum objective 2 would be done by the project feasibility analysis charpter. The curriculum supporting points for graduation requirements (Second level) is the 2.6. Teaching activities include the normal teaching, checking and Q \& A and experiment. The assessment link is also the Intermediate document.

(iii) Curriculum objective would be realized by the chapters of the feature design, interface design and database design. The curriculum supporting points for graduation requirements (Second level): is the 3.2. The training procedures are the normal teaching, checking and Q \& A and experiment. And the assessment link uses the GUI, Database and Intermediate document.

(iv) Curriculum objective 4 would be made by the software development, testing and optimization. The curriculum supporting points for graduation requirements (Second level) is the 3.3. The according training procedures are the normal teaching, checking and Q \& A and experiment; The assessment link are the database and intermediate document.

(v) Curriculum objective 5 should be finished by the project summary report. The curriculum supporting points for graduation requirements (Second level) is the 11.3. Teaching activities include the experiment and presentation and defense. The assessment link is the project report.

(vi) Curriculum objective 6 is displayed by the project presentation and reply. The curriculum supporting points for graduation requirements (Second level) is the 9.2. The training procedure would not be taken other time. The assessment link is the project demonstration.

The course assessment highlights the key of 'quantitative assessment'. Comprehensive evaluation is conducted from three aspects: learning attitude, learning process and learning results. The study attitude item would check the attendance and the project development record. The learning process has been examined by intermediate documents generated among the project. The effect of study has been set from two aspects of the final presentation defense and the summary report. The detailed assessment rules are shown in Table 2.

Table 2. Assessment rules

\begin{tabular}{|c|c|c|c|c|}
\hline \multirow{2}{*}{\multicolumn{2}{|c|}{ Assessment link }} & \multirow[b]{3}{*}{$\begin{array}{l}\text { Number of roll call is more than } 4 \text { times, absenteeism is deducted } \\
\text { according to the number of absence. }\end{array}$} & \multicolumn{2}{|c|}{ Score ratio $(\%)$} \\
\hline & & & \multirow{2}{*}{$\frac{\text { Percentage }}{10 \%}$} & $\begin{array}{r}\text { General } \\
\text { comment }\end{array}$ \\
\hline \multirow{6}{*}{$\begin{array}{l}\text { Usually } \\
\text { assessm- } \\
\text { ent }\end{array}$} & Attendance & & & \multirow{6}{*}{$50 \%$} \\
\hline & $\begin{array}{l}\text { Project } \\
\text { development } \\
\text { record }\end{array}$ & $\begin{array}{l}\text { Record detailed and regularized. Reflect effectively the progress of the } \\
\text { project. }\end{array}$ & $10 \%$ & \\
\hline & $\begin{array}{l}\text { requirement } \\
\text { analysis report }\end{array}$ & $\begin{array}{l}\text { 1. Make excellent, good, medium, passing, or poor evaluation according } \\
\text { to the report format layout and the content. } \\
\text { 2. If the report format is arranged according to the template, record the } \\
\text { score is the evaluation is excellent, and score is greater than or equal to } \\
90 \text { points if it meet the requirements and the content is deliberated } \\
\text { enough. } \\
\text { 3. Grade would be deducted based on the error and the lack of content } \\
\text { points. }\end{array}$ & $20 \%$ & \\
\hline & $\begin{array}{c}\text { Feasibility } \\
\text { analysis report }\end{array}$ & Rules are the same as the requirement analysis report. & $15 \%$ & \\
\hline & $\begin{array}{l}\text { Project design } \\
\text { report }\end{array}$ & Rules are the same as the requirement analysis report. & $30 \%$ & \\
\hline & $\begin{array}{c}\text { Software test } \\
\text { report }\end{array}$ & Rules are the same as the requirement analysis report. & $15 \%$ & \\
\hline \multirow{4}{*}{\multicolumn{2}{|c|}{ Final assessment }} & Source code. & $40 \%$ & \multirow{4}{*}{$50 \%$} \\
\hline & & Personal report (Performance of personal team role ) & $10 \%$ & \\
\hline & & Project summary report. & $10 \%$ & \\
\hline & & Project demonstration and defense. & $40 \%$ & \\
\hline
\end{tabular}




\section{Conclusion}

Adopting the OBE concept, the curriculum reform scheme of Application Software Development based on Java was designed in the CDIO engineering education mode. The scheme is a reverse design of the curriculum objectives, teaching procedures and knowledge capabilities for Application Software Development based on the graduation requirements. It guarantee the final learning achievement required by the course better.

Curriculum reform based on OBE is a repeated improvement process. It involves many aspects. Therefore, the scheme should also take the problems in the last practice round and the according measures, regular learning evaluation from students and teachers, and capability assessment(such as the typical teaching procedures, multi-mode teaching methods and the comprehensive application of teaching methods) into account. The scheme will be gradually improved in the future.

\section{Acknowledgement}

The paper was supported by the education and teaching research and reform project of Chengdu University of Information Technology (Y2015034). It is also the periodical achievement of the Computer Science and Technology (TS2488), which is one of the fifth Education Ministry Institution characteristic specialties.

\section{References}

[1] F. E. Zhang, J. F. Xue, and D. L. Li, Research on the training mode of CDIO engineering talents, Experimental Technology and Management, vol. 12, pp. 8-10, 2010.

[2] J. R. Liu, M. H. Wu, and Z. P. Li, Application of CDIO concept in the teaching reform of computer hardware practice course, Experimental Technology and Management, vol. 7, pp. $154-156,2011$.

[3] Q. Y. Zhao, L. Wei, The application of CDIO concept in the teaching reform of the Java series courses, Computer Knowledge and Technology, vol. 19, pp. 4681-4683, 2012.

[4] N. Li. Training of software engineering talents with high ability in CDIO engineering, Chinese Adult Education, vol. 3, pp. 107-108, 2010.

[5] P. H. Gu, W. L. Hu, and P. Lin, Engineering education mode based on "Outcome-based-Education" (OBE) -- The practice and exploration of Shantou University, Research in Higher Education of Engineering, vol. 1, pp. 27-37, 2014.

[6] Y. G. Yang, B. Meng, and W. N. Wang, Training of technological innovation ability based on OBE model, Research in Higher Education of Engineering, vol. 6, pp. 24-30, 2015.

[7] X.Sun, H. B. Cheng, The teaching reform of C language course based on OBE model, Journal of Ningbo Institute of Education, vol. 4, pp. 15-18, 2016.

[8] Y. Song, S. Hu, and C. Y. Yu, Research and practice of embedded control technology courses group based on OBE, Experimental Technology and Management, vol. 2, pp. 4-6, 2016.

[9] J. Bai, Y. R. Xie, and W. Li, Research on the resource structure model of online open Courses based on the concept of OBE in the "Internet plus" era, China Audiovisual Education, vol. 1, pp. 64-70, 2017.

[10] Q. Feng, Research on the training of Applied Talents in OBE education mode, Journal of Anhui Engineering University, vol. 3, pp. 81-85, 2016. 